\title{
2
}

\section{Role of Kaizen in Japan's Overseas Development Cooperation}

\author{
Kimiaki Jin
}

Japan International Cooperation Agency (JICA) has been working on the promotion of productivity improvement in different countries in the developing world as its Technical Cooperation (TC) project. One of the core systems of knowledge utilized in these activities is Kaizen as described in this book. It has a wide range of methodologies and tools with a very rich insight backed up by a long history of experiences. They are very scientific and analytical as well as human-centered. This chapter discusses factors affecting successful Kaizen promotion projects through reviewing the past projects in Southeast Asia, Latin America and some countries in Africa. It attempts to promote further understanding of Kaizen through disaggregation of several concepts based on theories of knowledge, learning and development cooperation. The chapter does not touch on details of technical tools which will be explained in other chapters (particularly in Chap. 3), but tries to connect its own arguments with the chapter on

K. Jin $(\bowtie)$

Japan International Cooperation Agency (JICA), Tokyo, Japan

e-mail: Jin.Kimiaki@jica.go.jp

(C) The Author(s) 2018

K. Otsuka et al. (eds.), Applying the Kaizen in Africa,

https://doi.org/10.1007/978-3-319-91400-8_2 
standardization (Chap. 4), the case in Ethiopia (Chap. 5) and the broader argument on industrialization in Africa (Chap. 6).

This chapter describes the history of Kaizen transfer based on the framework of TC. Section 2.2 explains the theoretical framework of TC in order to understand the characteristics of knowledge transfer. Section 2.3 reviews the history of Kaizen projects under the framework provided by Section 2.2. Section 2.4 sorts out key lessons and challenges of Kaizen knowledge transfer and elucidates the challenges of TC as well.

\subsection{Technical Cooperation (TC) in Japan's Official Development Assistance (ODA)}

Technical Cooperation (TC) of the Japanese government with overseas countries started in 1955 in combination with reparations for World War II, after Japan had joined the Colombo Plan in 1954. TC consists of programs of education and training at the home country or abroad, or services of consultants, advisors, teachers and administrators in recipient countries, according to the Organisation for Economic Co-operation and Development (OECD) glossary. ${ }^{1}$ In other words, TC is the provision of know-how to recipient countries in the form of personnel, training and research. In the case of a JICA TC project, a group of Japanese experts/consultants are dispatched to a recipient country and work together with the members of a counterpart organization. Although some parts of TC are provided to facilitate the implementation of loan and capital grant aid projects, Japan has been implementing TC as one of stand-alone activities to support capacity development of recipient countries under the category of bilateral grants.

The Japanese government established the Overseas Technical Cooperation Agency (OTCA) as an implementing body of TC in 1962 and reorganized it to the Japan International Cooperation Agency (JICA) by merging with the Japan Emigration Service (JEMIS) in 1974. Reflecting Japan's rapid economic growth created and sustained by its strong human resource base, and closer diplomatic ties with the

${ }^{1}$ http://www.oecd.org/dac/dac-glossary.htm\#TC 
Association of Southeast Asian Nations (ASEAN) countries, in 1981, Japanese Prime Minister Zenko Suzuki announced the launch of a comprehensive package of human resources development projects in ASEAN countries $^{2}$ as a part of its Official Development Assistance (ODA). One of the projects in five ASEAN countries was the Productivity Development Project (PDP) in Singapore that started in 1983 and which lasted for a period of seven years, which attempted to transfer various Kaizen knowledge and tools. This is because then Prime Minister Lee Kuan Yew of Singapore specifically requested the Japan Productivity Center (JPC) to transfer Japan's productivity development movement to the country (NPB and JICA 1990; JICA 2014b). In Thailand, JICA started the Productivity Development Project in 1994 which lasted for five years. Kaizen has become a symbolic know-how that Japan has transferred to Singapore and other developing countries as one of the secrets of Japan's economic achievement in the postwar period. And the transfer of Kaizen is one of the significant successes that Japan has contributed to the industrial development in Singapore ${ }^{3}$ and Thailand through human resource development. In this way, TC of Japanese ODA has become one of the major instruments to transfer know-how of productivity improvement to developing countries, whose details are explained in Section 2.3 of this chapter.

Japanese ODA including TC has been enjoying good reputation among recipient countries in East Asia. However, among Western donors, technical assistance which mainly associates with implementation of capital investment projects was not so appreciated especially in the context of sub-Saharan Africa's development. The concepts of TC and technical assistance (TA) have been (and continue to be) used interchangeably in many arguments in the development discourse. Both TC and TA have the same goal of capacity building in many cases. However, there are attempts to distinguish between the two terms, as pointed out by McMahon, a World Bank consultant. His analysis suggests that TC is broader in focus, trying to increase the level of knowledge, skills, technical

\footnotetext{
${ }^{2}$ http://www.mofa.go.jp/mofaj/gaiko/bluebook/1982/s57-shiryou-401.htm

${ }^{3}$ The government of Singapore organized the national productivity movement from 1981 that JICA has supported through its TC, which accelerated economic growth of the country.
} 
comprehension or productive aptitudes of residents of a developing country. In contrast, TA refers to activities whose main contribution is to design or implement a given project or program (McMahon 1997).

In 1996, the Operations Evaluation Department of the World Bank evaluated TA provided by the Bank between 1971 and 1991. Its report points out that to design institutional development (ID), TA requires an intimate knowledge of local practices and how decisions are really made, since ID efforts are very sensitive to cultural, social and political factors beyond the control of project management (WB 1996). The report states that out of 1689 approved projects during 1971-1991, only 29\% of them have sufficient impact on ID. The report concludes that although the outcomes of TA have varied widely, the efficacy and cost-effectiveness of TA overall has been disappointing, especially in sub-Saharan Africa. Another point is that TA is often donor- (or supplier-) driven with little commitment of recipient countries (McMahon 1997). Although there are several arguments on the effectiveness of TA, the overall conclusion of the World Bank is that it has been a microcosm, donor-driven, with little evidence that it has done much to improve local institutions (Morrison 2005). Other donors concerned with aid effectiveness such as the Department for International Development (DFID) now share a similar understanding that technical assistance is not very effective, partly because of the high transaction costs that are involved (Killick 2008).

Based on the above arguments, TC was often criticized by some of the Western donors as failing to meet actual recipient countries' needs. Therefore, Japan's TC project was also viewed as "old-fashioned" and "inefficient" assistance among Western donors (Arase 2005). Even recently, Kodera (2016) points out that JICA's TC and training programs have not received due attention from the bankers of multilateral financing institutes because of TC's micro-nature and also JICA's inability to articulate its own know-how accumulated on the ground in an international context. Therefore, there is a pressing need for JICA to scale up impact of TC as well as to convert JICA's plenty of tacit knowledge on technology transfer into an explicit one and share it with the international society.

The other part of arguments on TC is much more positive, symbolized in the concept of capacity development, which the next section explains. In the framework of ODA in Japan, TC has been a vital tool to accelerate economic growth in the context of development in East Asia. One of the 
arguments is about Japan's ODA Model that was presented by the working group of economic cooperation in the national council of industrial structure of Japan as a very successful model of development cooperation (METI 2005). The concept of the Japan's ODA Model is a combination of hard infrastructure development through capital aid, soft infrastructure and industrial human resource development through TC, which stimulate production, trade and investment by the private sector. In fact, Japanese ODA has been a major tool that contributes to economic growth in Southeast Asia.

The TC has been particularly focusing on development of human skills and know-how, technical guidelines, vocational training and higher education, institutional setup, regulatory frameworks, quality control and standardization system for the country as well as for the region. These focuses on industrial development show clear contrast with the ODA by the Western donors which shifted away from industrial development and concentrated on the social sector particularly since the 1990s.

Kato (2016) lists human resources development and field orientation as key characteristics of Japan's ODA. He points out two focuses of human resource development to cooperation; one is formal education, particularly basic education, and another is cooperation that nurtures people's practical problem solving capacity. The latter includes promotion of the Kaizen-type problem solving activities as a typical Japanese model. He added that many development practitioners involved in JICA projects believe that this type of capacity can be acquired through experience in the workplace (gemba). Human resource development is an absolute priority unanimously upheld by Japanese development workers almost like an obsession, according to Kato. The following sections elaborate this concept of human resource development through illustrating the experience of transfer of Kaizen.

\subsection{Theoretical Framework of Technical Cooperation}

Kaizen is a set of knowledge, methodologies and tools for quality and productivity improvement as broadly described in Chap. 1. It has been transferred to developing countries as a part of Japan's TC projects aiming at knowledge transfer and institutional setup. However, as the World Bank report correctly stated, TC for institutional development is very sensitive 
to cultural, social and political factors of the recipient countries. Therefore, in order to understand the challenges of Kaizen transfer to developing countries, how the JICA's TC has managed to deal with such influential factors needs to be explained. The key concepts to manage them are (1) "customization of knowledge" through collective work of local and foreign experts, (2) practical approach through "learning by doing" in addition to classroom or seminar-type trainings and (3) leading and supplementary roles of the public sector. By the way, in the author's terminology, the word "localization" and "customization" are interchangeable. Localization is a concept of modification explained from the viewpoint of the supply side who works on "standard" approaches. The word "customization" is one from the recipient side who works on its own reality on the ground. Technical application of Kaizen methodologies and tools is described in Chap. 3 by Sugimoto, and this chapter focuses on the soft part of Kaizen knowledge transfer to developing countries.

\subsubsection{Customization of Knowledge}

A typical process of development begins with an introduction of a scientific and rational way of doing things into traditional systems of the society. In many cases, scientific and rational approaches are of Western origin. Japan has experienced a dramatic introduction of such modern Western ways of doing things into traditional Japanese systems, first through the Meiji Restoration starting in 1867 and second after defeat in World War II in 1945. In both experiences, Japanese society was necessitated to accept and digest Western ways of new technologies and incorporate them into its own systems in order to secure its diplomatic survival and promote reconstruction of the country. Development of the Kaizen approach that is started from introducing the concept of productivity management from the US is one of symbolic efforts of the country.

Through the modernization process of Japan during the Meiji Restoration, there was a key concept shared among Japanese people, which is the Wakon Yosai [Japanese spirit, Western knowledge] approach. This is because people know that the society prefers to maintain its own cultural and traditional system as core values through development while accepting 
external knowledge and technologies. Knowledge is always linked with the culture and environment from which it comes. And knowledge is deliberately interpreted to be applicable to the social values and environment of which it goes in. This balanced process is one of the key factors for successful introduction of new knowledge, even under the recent and rapid globalization. Development of Kaizen based on the US technology is a process of customizing foreign knowledge and improving along the context of its own. Sawamura (2002) argues that this Wakon Yosai approach based on Japan's own experience of modernization as a non-Western developed country provides foundations for Japanese development cooperation.

Kaizen systems and methodologies consist of two major dimensions. One is a rational and scientific dimension based on measurement, calculation and standardization, or engineering dimension in other words. Another is a human-focused participatory dimension that is often called as "Kaizen philosophy" or "Kaizen mind-set." These two dimensions, engineering and human-focused, are contrasting and often analyzed and discussed in different development discourses. Engineering parts are common knowledge applied globally while human-focused parts are always social context-specific. Chambers (1997) points out that an engineering issue can be managed by a top-down, blueprint approach that is essential for physical construction. On the other hand, the issues related to people have uncontrollable and unpredictable features. He argues that many of the errors of development effort have followed from trying to apply the blueprint approach, which works with controllable and predictable things, to processes with uncontrollable and unpredictable people. Even in the manufacturing industry, the human features are not negligible as far as production process depends on human labor and management. Therefore, the double rational/scientific and human-focused dimensions in Kaizen are a result of the efforts of how to apply the engineering approach to Japanese society. Because Kaizen has such humanfocused participatory dimension, it is applicable in different societies if it is properly managed and adjusted in the local context. That is already proved through the process of successful dissemination of Kaizen in the US, Europe, Asian countries and other parts of the world.

The participatory approach is essential to customize or at least adjust Kaizen activities to each workplace environment, since many people 
often resist changes brought externally. However, Nonaka's knowledge creation theory in which the Japanese approach has its foundation provides further advantage of the participatory approach. Nonaka (1991) points out the importance of tacit knowledge by quoting the words of a philosopher, "we can know more than we can tell." His theory is constructed through analyzing the processes of innovation in Japanese major manufacturing companies. During application of Kaizen tools to a company, managers and workers who participate in the process can propose useful ideas even without knowing logical justification explicitly. Nonaka and Toyama (2003) further argue that knowledge is a reality viewed from a certain angle. The same reality can be viewed differently depending on from which angle or context one sees it. They argue that people have their own cultural and historical contexts which give the basis for one to interpret information to create meanings. These arguments imply that effort of knowledge transfer from outside of the society, such as TC, needs to be built on intensive interaction between those who see the reality from different angles. One of the key features of Kaizen promotion in the countries JICA has been working with is customization of original Kaizen in the context of the working culture and environment in the recipient country through participatory process of management and frontline workers in companies.

As a result, JICA's Kaizen concept applied to its TC projects covers a much broader concept of productivity improvement activities than the narrow sense of the Kaizen definition shared within Japanese manufacturing industries. In developing countries, the capacity of people at the beginning of the project is quite different from the one in Japan, so the emphasis on how to utilize the variety of Kaizen tools should also be different. $5 \mathrm{~S}$ (sort, set in order, shine, standardize and sustain), a basic tool of housekeeping, plays quite an important role in the initial stage of Kaizen introduction as stated in the latter part of this section, which is one of customization through TC. On the other hand, in the US, Kaizen was further developed to Business Process Reengineering (BPR), Lean Manufacturing and Six Sigma, as described in Chap. 4, based on its technical level of industry as well as characteristics of the national labor market and the employment systems in the US. The author assumes that the approach of productivity improvement can be more engineering-oriented, 
such as BPR, under the condition of a dynamic labor market, in which workers are easily replaceable. In contrast, in the customary society with a static labor market and long-term employment system, the approach may be more human factor-oriented.

Furthermore, the International Organization for Standardization (ISO) based in Switzerland is promoting standardization of productivity improvement in which Six Sigma is a core system promoted as global knowledge (see Chap. 4). In contrast, the Japanese Kaizen approach has a characteristic to adjust itself to the local context and incorporate local knowledge, if properly handled by people who know such local contexts. Quality Control (QC) Circle is a tool to utilize such local knowledge in the company level into Kaizen activities while stimulating ownership and satisfaction of workers, although further customization is required for effective operation as explained in Section 2.4 of this chapter.

\subsubsection{Learning by Doing}

Another point to understand Kaizen knowledge transfer by TC is "learning by doing," which is also related to a characteristic of knowledge. In the context of knowledge transfer for development, King and McGrath (2004) refer to two broad tendencies in theory and practice. One tendency is that knowledge is universally applicable and can be captured in a set of synthesized notes on best practice and hence be transferable. This is termed the technological approach. Another broad tendency is termed the social approach, which emphasizes that much of what is really useful knowledge is embedded in the experience of individuals and could not be easily captured and codified, such as tacit knowledge. This thought emphasizes the importance of learning together, which may be designated as experiential approach. King argues that the Japanese approach focuses more on learning-by-doing, experience-based approach and context-specific knowledge than the Western type of approach that focuses on codified knowledge such as the UK's. This argument explains that the effective transfer of knowledge such as Kaizen from Japanese experts to counterparts needs experience-sharing through collective work at gemba in addition to provision of manuals and classroom training. For 
implementation of JICA's TC projects, Japanese Kaizen experts always work together with their counterparts through on-the-job training (OJT) in the recipient organization and target companies.

With regard to the concept of capacity development, JICA's Capacity Assessment Handbook (2008) disaggregates capacity to technical capacities, core capacities and enabling environment. Technical capacities refer to specialized knowledge and skills of particular sectors and technologies. The core capacities are the central force in capabilities in handling issues such as discipline, will, attitude, leadership and management capabilities which are needed for producing desirable results through the use of technical capacities. The core capacities are complex and have a nature whereby they can only be improved by following a complicated course that contains such steps as learning through trial and error, inner reflection and self-development. Figure 2.1 shows the image of capacities particularly emphasizing the importance of the core capacities by using an iceberg as a metaphor. A major part of the core capacities is invisible because it is underwater but sustains visible parts of capacities. Kaizen activities in their basic stage can address the formation of these core capacities through learning by doing $5 \mathrm{~S}$ (sort, set in order, shine, standardize and sustain).

\section{Visible}

Presence and changes are visible

Technical

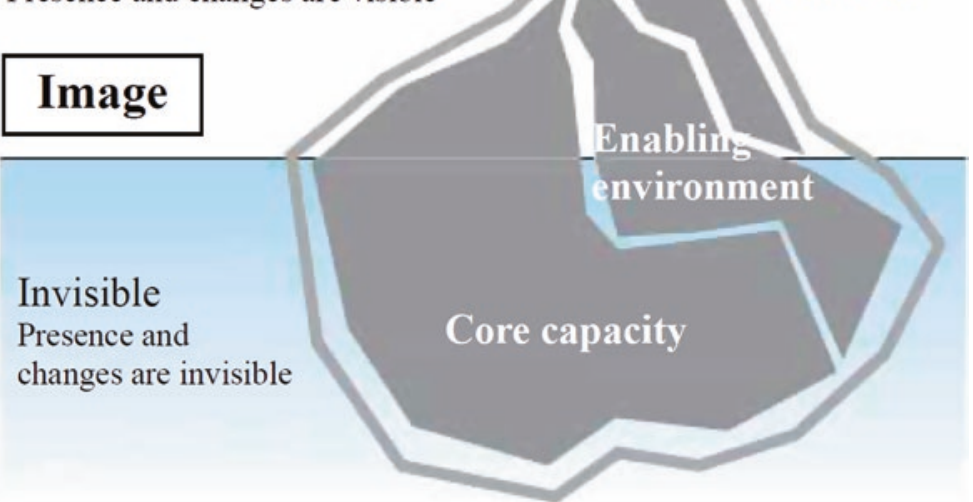

Fig. 2.1 Image of capacities. (Source: JICA Capacity Assessment Handbook (2008)) 
These core capacities are related to people's mind-set on punctuality and obedience to the rules, which have far-reaching impact on operation and maintenance of machineries, infrastructure and performance of service delivery. In many developing countries especially in sub-Saharan Africa, development of core capacities for a mass of people is crucial for further development of technical capacities.

Moreover, for the localization/customization process, in many cases, the right focuses and points of adjustment that should be made are not known before actual application on the ground. There is always a risk of failure as well as potential of improvement to be better. Therefore, trial and error is an effective process, which is also shared by Western academics such as Easterly (2006), who highly values the "searchers" position. He points out that "searchers" admit that they do not know the answers in advance and try to disentangle complicated political, social, institutional and technological factors. These features require the "learning-by-doing" approach.

Table 2.1 shows the classification of capacity development activities divided into institutional development and human resource development of individuals, and further break down to technical aspects and human aspects. Human aspects of both institution and human resources can be developed through the participatory approach and core capacity can be developed through learning by doing. Each part is mutually influential and regulative, and so the learning-by-doing approach is one of essential building blocks for comprehensive capacity development.

Table 2.1 Disaggregation of capacity development

\begin{tabular}{|c|c|c|}
\hline & Technical aspects & Human aspects \\
\hline $\begin{array}{l}\text { Institutional } \\
\text { development }\end{array}$ & $\begin{array}{l}\text { Institutional structures, } \\
\text { infrastructure, equipment, } \\
\text { IT, resource allocation }\end{array}$ & $\begin{array}{l}\text { Decision-making system, } \\
\text { labor management system } \\
\text { (and corporate culture) }\end{array}$ \\
\hline $\begin{array}{l}\text { Human capacity } \\
\text { development }\end{array}$ & $\begin{array}{l}\text { Technical capacity (sector- } \\
\text { specific technologies, skills } \\
\text { and knowledge } \\
\text { management) }\end{array}$ & $\begin{array}{l}\text { Core capacity (discipline, } \\
\text { will, attitude, motivation, } \\
\text { leadership of individuals) }\end{array}$ \\
\hline
\end{tabular}

Source: Created by the author 


\subsubsection{Role of the Public Sector}

Since Kaizen is a set of know-hows applied in industry, foreign direct investments (FDIs) can be a vehicle of transferring to developing countries. In fact, many Japanese private companies which invest in Asian countries disseminate Kaizen in the region. However, the history shows that the public sector can accelerate its transfer by a series of supportive arrangements. Moreover, there are critical arguments of leaving technology transfer to market mechanisms (see Chap. 6).

Prime Minister Meles Zenawi who decided to bring Kaizen to Ethiopia explained his intention on technology transfer in his article on the Developmental State (Zenawi 2012). He pointed out that technology cannot be efficiently supplied to developing countries by the market mechanism because of the virtuous cycle of knowledge creation established through joint actions of the public and private sectors in developed countries and the vicious cycle of the low-technological development trap unbreakable by market forces in developing countries. Hence, he argued that non-market intervention is needed for developing countries to accelerate their catch-up process. Stiglitz and Greenwald (2014) also assert that investment in learning and innovation may not be optimal in unfettered markets because they are characterized as being public goods with spillover effects and sunk costs.

Even without knowing such academic arguments, the Japanese government has been proactive to introduce foreign knowledge from abroad and provided technical support to the private sector during Japan's catch-up process and economic growth. The Japanese government has also been providing TC to developing countries especially in Southeast Asia, particularly focusing on small and medium-sized enterprises (SMEs) in the field of industrial development. This is because SMEs are not in an advantageous position in technology transfer or the acquisition process, but the presence of them who can enter into the supply chain of FDIs as a supporting industry is essential for sustainable economic growth. And because FDIs limit their technical support to current subcontractors, there is room for the public sector to provide technical support to wider but selected SMEs who are conscious about productivity improvement and willing to enhance their supply capacity. Chapter 6 of this book analyzes the role of the public sector in provision of Kaizen training, which supports capacity 
Table 2.2 Transfer of Kaizen from Japan to developing countries

\begin{tabular}{|c|c|c|c|}
\hline & Japan & & Developing countries \\
\hline \multirow[t]{2}{*}{ Public domain } & $\begin{array}{c}\text { JICA and } \\
\text { the expert team }\end{array}$ & & $\begin{array}{l}\text { The organization } \\
\text { providing business } \\
\text { development services }\end{array}$ \\
\hline & $\uparrow$ & $\mathrm{TC}$ & $\begin{array}{cc}\downarrow & \text { Training/ } \\
& \text { Consultancy } \\
& \text { Services }\end{array}$ \\
\hline \multirow[t]{2}{*}{ Private domain } & Companies & & Companies \\
\hline & & FDIs & \\
\hline
\end{tabular}

Source: Created by the author

development of entrepreneurs as well as identifies promising ones for further support. To accelerate industrialization, the public sector can play more roles in infrastructure development and finance.

Table 2.2 shows a concept of complementarity of FDIs and TC in Kaizen promotion in Southeast Asia that is explained in the next section. Though the main channel of Kaizen transfer is from companies in Japan to companies in developing countries through FDIs, JICA mobilizes Japanese experts and transfers Kaizen to the organization who promotes productivity improvement in the developing country, such as the National Productivity Board in the case of Singapore. The organization further transfers Kaizen to private companies in the country.

Through Japanese TC projects, Kaizen is also applied to hospital management in Sri Lanka and 15 other countries in Africa. The main approach of these projects is to introduce $5 \mathrm{~S}$ and Total Quality Management (TQM), which improve working environment of hospital staff and subsequently improve quality of services, occupational safety and motivation of the staff. In this case, the role of the public sector is unarguably important.

\subsection{Kaizen Dissemination in the ODA Framework}

In Southeast Asia, JICA implemented productivity development projects in Singapore and Thailand. The one in Singapore started in 1983 and has a monumentally high profile. It was on a large scale in terms of the 
number of Japanese experts involved in TC because of commitments of high-level political leaders in both countries. In the case of Thailand, the project was affected by the Asian financial crisis in 1997 and extended for two years. Apart from these two countries, Malaysia also introduced Kaizen by its own efforts without JICA. Since the 1990s, JICA has been expanding its Kaizen promotion to Latin America, and to Africa which started during the boom since the latter part of the 2000s. Figure 2.2 shows a list of the past and ongoing JICA projects on productivity improvement ${ }^{4}$ in various parts of the world and their periods of cooperation.

\subsubsection{Cases in Southeast Asia}

Singapore is the first country that JICA has provided TC on quality and productivity development. Based on the request from Prime Minister Lee Kuan Yew, JICA started its Singapore Productivity Development Project (PDP) as a TC in 1983 and continued until 1990. The counterpart in the Singaporean side was the National Productivity Board (NPB) that was established in 1972 under the Ministry of Labor. Prior to the request of the project to the Japanese government, the Singaporean government launched the national productivity movement and NPB published a report of the Committee on Productivity in 1981 that analyzed the "Japanese System" of productivity improvement with around 30 recommendations to its own government regarding management and labor systems to be introduced in Singapore (JICA 1986). In 1981, Prime Minister Lee also discussed with the Chairman of $\mathrm{JPC}^{5}$ who is one of the main promoters of the Kaizen movement in Japan. Although the initial concept of the human resource development project had focused on vocational training, the Singaporean government changed its subject to productivity improvement based on such preparation. Table 2.3 shows the chronology of the PDP formulation and implementation.

\footnotetext{
${ }^{4}$ The table shows only the projects focusing mainly on productivity improvement. There are many other projects supporting SME development, which are not indicated in the list.

${ }^{5}$ The Chairman of JPC was Mr. Kohei Goshi who also visited Singapore to discuss with PM Lee, according to an interview with JPC staff.
} 


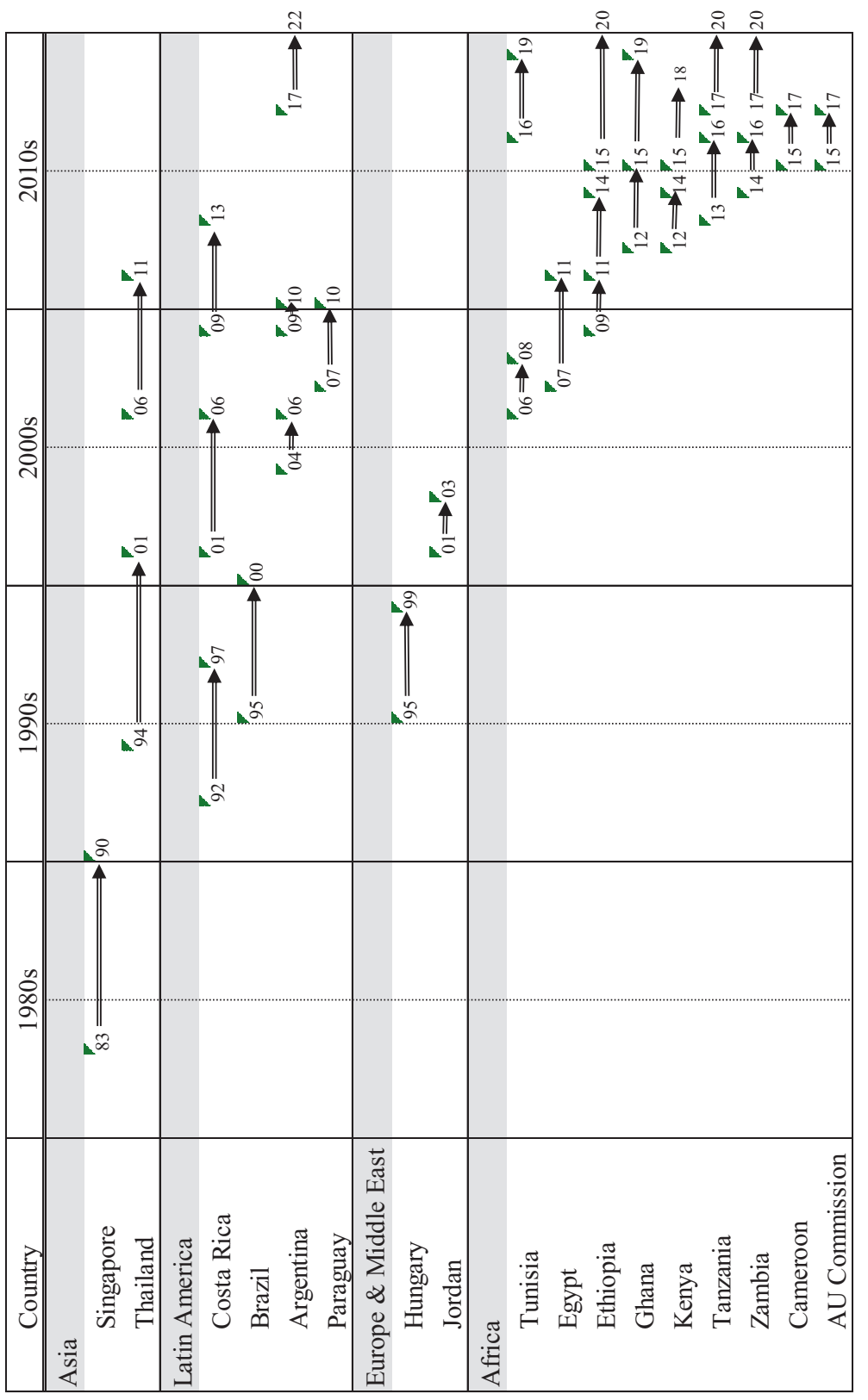

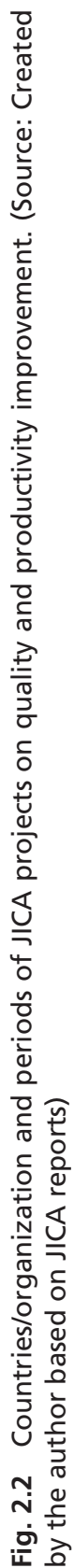


Table 2.3 Chronology of Singapore PDP

\begin{tabular}{|c|c|c|}
\hline 1972 & & NPB was established \\
\hline \multirow[t]{3}{*}{1981} & Jan & $\begin{array}{l}\text { PM Zenko Suzuki of Japan committed to the ASEAN Human } \\
\text { Resources Development Project }\end{array}$ \\
\hline & Apr & $\begin{array}{l}\text { The Singaporean delegation proposed to set up an Institute for } \\
\text { Continuing Occupation Development at the meeting in Tokyo }\end{array}$ \\
\hline & Jun & $\begin{array}{l}\text { PM Lee Kuan Yew of Singapore met Kohei Goshi, Chairman of } \\
\text { Japan Productivity Center }\end{array}$ \\
\hline \multirow[t]{2}{*}{1982} & Mar-Jun & $\begin{array}{l}\text { The Ministry of Labor and NPB decided to re-propose a project } \\
\text { focused on the productivity movement }\end{array}$ \\
\hline & Jun & $\begin{array}{l}\text { A Singaporean mission to Japan presented a new project } \\
\text { proposal on PDP }\end{array}$ \\
\hline \multirow[t]{2}{*}{1983} & Jun & $\begin{array}{l}\text { Signing of the project agreement (the Record of } \\
\text { Discussion) and preparatory phase started }\end{array}$ \\
\hline & Oct & $\begin{array}{l}\text { A first group of long-term Japanese experts was sent to } \\
\text { Singapore }\end{array}$ \\
\hline 1985 & Apr & Restructuring phase started \\
\hline 1986 & Nov & Implementing phase started \\
\hline 1988 & Jun & Consolidation phase started \\
\hline 1990 & Jun & The project ended \\
\hline
\end{tabular}

Source: Created by the author based on NPB and JICA (1990)

The PDP started as a five-year project in 1983 and was extended for two years until 1990. Progress of the project is summarized in four phases, namely, the preparatory phase (June 1983-March 1985), the restructuring phase (April 1985-October 1986), the implementing phase (November 1986-June 1988) and the follow-up or consolidation phase (June 1988June 1990) (NPB and JICA 1990). In the preparatory phase, initial efforts were made by Japanese experts to promote understanding of the Singaporean side on the basic theory and concept of the Japanese productivity movement based on Kaizen before practicing actual tools in the field. This is because the JICA's preparatory mission of the PDP pointed out that the Singaporean side understood the complicated management system of Japan superficially (JICA 1986). However, such theoretical approach could not satisfy NPB staff so, in the restructuring phase, the approach was changed ${ }^{6}$ to a more practical application of Kaizen tools in order to show tangible improvement in industries first and then proceed

\footnotetext{
${ }^{6}$ The Japanese side discarded tens of thousands of pages of textbooks prepared for the PDP before its start, in order to show a clear change of approach to the Singaporean side, according to the interview with JPC staff.
} 
to understanding the concept (JPC 1990). On-the-job training for the NPB staff was introduced to equip them with relevant skills, which was a typical "learning-by-doing" approach adopted in the reconstructing phase. In the implementation phase, the role of Japanese experts shifted from leaders of activities to advisors to NPB staffs who became actual consultants to provide training and consultation services to the companies. In the consolidation phase, fundamental productivity practices such as $5 \mathrm{~S}$ were firmly entrenched in the industry.

Throughout the project, the following fields and methodologies of Kaizen were covered:

- Management and Supervisory Development (MSD)

- Labor-Management Relations (LMR)

- Quality Control Circles (QCC)

- Industrial Engineering (IE)

- Total Quality Control (TQC)

- Audio-Visual (AV) Technology

- Productivity Measurement

- Occupational Safety and Health

- Consultancy for Small and Medium Enterprises

Concrete indicators of outputs of the project were:

1. 196 Singaporeans were trained in Japan,

2. over 200 Japanese experts were dispatched and exposed to Singaporean industries,

3. 4000 participants were trained using materials developed by PDP,

4. more than 200 SMEs have benefited from assistance given by the NPB consultants and Japanese experts,

5. SMEs can seek assistance from a pool of the 191 referral consultants and 30 associate consultants set up by the NPB,

6. $5.4 \%$ of the whole workforce in the country became members of the QCC, and

7. over 100 companies introduced 5S (NPB and JICA 1990).

These outputs further contributed to the annual growth rate of productivity in Singapore, which was 4.5\% between 1980 and 1995, as the 
then Deputy Prime Minister Tony Tan Keng Yam acknowledged ${ }^{7}$ at the inauguration of the 1996/1997 productivity campaign in Singapore. At the end of the project, JPC (1990) which is the main player of the project in the Japanese side published a retrospective report on lessons learned from the project. It says that the project had focused on TQC, QCC and IE as priority target methodologies of TC in the restructuring phase. However, through the activities on the ground, the project members realized that neither workers of most factories were well organized nor factories were clean. Although the NPB side requested to learn Total Productive Maintenance (TPM), real problems in the factories were far basic than the level of TPM, and the capacity of the NPB staff was not as high as expected. Therefore, Japanese experts re-proposed to introduce $5 \mathrm{~S}$ as an initial step and gradually proceed to higher technologies. The JPC report also points out that the management technology is a comprehensive technology consisting of both science/engineering and sociology/human science, so that its essence would be understood only after applying to the actual workplace of production and services. The report further states that the Singaporean side should develop their own guiding principles of productivity improvement instead of applying the three guiding principles of productivity movement in Japan (expansion of employment; cooperation between labor and management; and fair distribution of the fruits of productivity improvement among labor, management and consumers).

Ohno and Kitaw (2011) draw several lessons from the PDP in Singapore. First, productivity improvement needs strong commitment from higher-level officials, organizations and individuals. Second, it needs a strong organization structure for policy coordination. Third, a cadre of private management consultants needs to be nurtured. These institutional frameworks can be the essence of creating productivity movement in any country.

In Singapore, much more advanced methodologies/tools of productivity improvement are now widely applied to various fields. Cirera and Maloney (2017) reported the cooperation between JPC and NPB (now known as SPRING) as a good case of a productivity program. Considering

\footnotetext{
${ }^{7}$ Press release saved at the National Archive of Singapore at http://www.nas.gov.sg/archivesonline/ data/pdfdoc/1996103101/tkyt19961031s.pdf
} 
current high economic competitiveness and technological advancement of the country, although productivity improvement is a result of a variety of influential factors, the author assumes that the productivity movement supported by PDP has created a foundation for the current economic success of the country. It is also worth mentioning that Kaizen has complementarity to other industrial development support measures that government can provide such as business development services and finance (JICA 1997; Lemma 2016). In fact, the NPB has further evolved into the Productivity and Standard Board (PSB) in 1996 and then the Standards, Productivity and Innovation Board (SPRING) in 2002 and now is providing support to enterprises in financing, capability and management development, technology and innovation, and access to markets. ${ }^{8}$ This process of institutional development implies that Kaizen provides foundation for further creation of innovation.

In Thailand, the government established the Thailand Management Development and Productivity Center (TMDPC) in 1962 with the support of the International Labor Organization (ILO). In order to increase productivities of the country, the government planned to promote national-level productivity movement and requested TC to the Japanese government in 1991, which aimed to train the TMDPC for effective implementation of the movement. The Thailand Productivity Development Project started in 1994 and continued until 2001 (JICA 2000a). In 1995, the Thai government established a new institute, the Thailand Productivity Institute (FTPI), from here on the project was handled by FTPI. The project trained 46 counterparts, organized "Productivity Week," introduced 5S to the Prime Minister's Office and provided on-the-job training on On-site-Management Guidance to around 100 companies. Approximately 200 companies have visited the institute for consultation. In 1997, Thailand was hit by the Asian Financial Crisis, and the government launched the Industrial Reconstructing Plan in 1998, in which improvement of productivity was one of the issues to strengthen competitiveness of the country. The project was extended for two years to concretize its outputs. There was a negative phenomenon in the project; during the process of changing the

\footnotetext{
${ }^{8}$ https://www.spring.gov.sg/About-Us/Pages/spring-singapore.aspx
} 
counterpart organization from TMDPC to FTPI in 1995, many TMDPC staff refused to move to the new institute because FTPI was planned to be privatized after five years. They were afraid of losing the status of public servants (JICA 1999).

The economy in Thailand has been dynamic and successfully fostering the development of the automotive industry. In 2005, total production of cars in the country was more than 1 million per year. In 2006, in collaboration with the Japan External Trade Organization (JETRO) and the Association for Overseas Technical Scholarship (AOTS) ${ }^{9}$ in Japan, JICA launched the Automotive Human Resources Development Project for Supporting Industries for a period of 5 years in order to develop the dynamic supporting industry in Thailand. One of four major fields covered by the project was the Toyota Production System (TPS) that included Working Control, Continuous Flow, Standardized Work, and the Pull System. Kaizen is already incorporated into major production systems of manufacturers in Thailand as FDIs especially from Japan disseminated it in the 1990s and after. Therefore, demand for Kaizen was already high among SMEs in Thailand at the time when the project started (JICA 2004).

In the case of Malaysia, the National Productivity Center was established in 1962, which was reorganized as the National Productivity Corporation (NPC) in 1991 and again renamed as the Malaysia Productivity Corporation (MPC) in 2008. The NPC has been collaborating with JPC under the membership of the Asian Productivity Organization (APO) since 1983 as well as with the Union of Japanese Scientists and Engineers (JUSE) to promote QCC without involvement of JICA. The MPC has been enthusiastically promoting $5 \mathrm{~S}$ by creating the $5 \mathrm{~S}$ certificate and $5 \mathrm{~S}$ audit.

In other Southeast Asian countries, FDIs by Japanese firms are major vehicles for Kaizen transfer. In these countries, although JICA hasn't implemented TC exclusively focusing on quality and productivity improvement, many TCs in industrial development have included training modules on Kaizen. The Association for Overseas Technical

\footnotetext{
${ }^{9}$ The Association for Overseas Technical Scholarship (AOTS) was established in 1959, reorganized to the Overseas Human Resources and Industry Development Association (HIDA) in 2012 and again changed to the Association for Overseas Technical Cooperation and Sustainable Partnerships (AOTS) in 2017.
} 
Cooperation and Sustainable Partnerships (AOTS) in Japan is another implementing arm of Japanese ODA, who also provides Kaizen training to Asian countries. From 1980 until 2016, the AOTS received 16,560 training participants who joined the courses with Kaizen as a part of subjects and dispatched 2482 experts $^{10}$ to Asian countries. Moreover, JPC and JUSE have been independently expanding networks on quality and productivity improvement to Asian countries such as through the International Convention on Quality Control Circles.

These efforts on industrial human resources development focusing on quality and productivity improvement are essential parts of contributing factors of East Asian economic growth in conjunction with economic infrastructure development and promotion of investment climate (see Chap. 6).

\subsubsection{Cases in Latin America}

In Costa Rica, JICA had supported the Technical Instructor and Personnel Training Center for Industrial Development in Central America (Centro de Formacion de Formadores y Personal Tecnico para el Desarrollo Industrial de Centroamerica-CEFOF) in three phases-from 1992 to 1997, from 2001 to 2006 and from 2009 to 2013. CEFOF was established in 1992 as a community college for the purpose of training technical personnel in the industry of Central America. Through JICA's support, CEFOF had been providing training courses on 5S, Problem Solving Techniques, QC Seven Tools, TPM, Supervisory Training, Computer Applications as well as consultancy services on introduction of $5 \mathrm{~S}$ to the companies. $\mathrm{CEFOF}$ also provided a training program mainly focusing on $5 S$ to the companies in the Central America region (JICA 2005). At the end of the third phase, CEFOF had developed a network of consultants/ facilitators/institutions working on productivity improvement to share information and provide support. CEFOF had organized seminars covering eight countries ${ }^{11}$ in which 1797 participants were involved during the third phase period. A total of 56 consultants became certified facilitators on Japanese quality and productivity improvement (JICA 2014a).

\footnotetext{
${ }^{10}$ Data obtained from AOTS in August 2017.

${ }^{11}$ Belize, Costa Rica, Dominican Republic, El Salvador, Guatemala, Honduras, Nicaragua, Panama.
} 
CEFOF became an organization under the Costa Rica Technical University (UTN) and was renamed as Centro de Calidad y Productividad-CECAPRO during the third phase of the project.

In Brazil, Instituto Brasileiro Qualidade e Produtividade in Parana (IBQP-PR) was a counterpart organization of the productivity and quality improvement project supported by JICA. Because IBQP-PR was a newly established institute when the project was started, the evaluation report of JICA (2000b) points out the importance of gradual approach with a flexible project design. The report also emphasizes the importance of on-the-job training as well as presentation of tangible results in addition to theoretical knowledge transfer.

In Argentina, JICA supported Instituto Nacional de Tecnologia Industrial (INTI) in two phases, from 2004 to 2006 and from 2009 to 2010, which focused on a supporting program for SME development. INTI and JICA launched the third phase in 2017 in which Kaizen would play an essential role in training programs supported by the projects. INTI retains around 100 consultants as its own staff who are working as a Kaizen trainer or a Kaizen instructor. This continuous and extended relationship between INTI and JICA proves the effectiveness of Kaizen application in Argentina (JICA, UNICO and JPC 2018).

In Paraguay, JICA supported Centro Paraguayo de Productividad y Calidad (CEPPROCAL) from 2007 to 2010 in order to strengthen its capacity for business consultation to SMEs and as a training provider. Through the cooperation with JICA, CEPPROCAL has developed a system to provide its services to SMEs by utilizing external personnel of the organization as pooled consultants (JICA 2009).

\subsubsection{Cases in Africa}

In the African continent, JICA has been supporting quality and productivity improvement in eight countries consisting of Cameroon, Egypt, Ethiopia, Ghana, Kenya, Tanzania, Tunisia and Zambia as shown in Fig. 2.2. All of the JICA projects in the African continent started after 2005 under the environment in which many African countries were achieving high economic growth. These countries particularly in sub- 
Saharan Africa intend to achieve economic transformation through improving the productivity of their industries and service sectors and upgrading their competitiveness in the international market without relying on the price hike of oil and minerals produced in this continent. In addition, the African Union Commission (AUC) introduced Kaizen in 2009 by obtaining the support of the Spanish government for their own reform of the internal administrative system. Imai (2012) reports the case of the AUC as a model of removing Muda from the public sector organization in his second edition of Gemba Kaizen. He presents the 4P model (Physical workplace improvement, Process improvement, Policy review, and People involvement) for the AUC as a result of customization of Kaizen. From 2015, JICA has followed this effort and supported AUC Kaizen promotion that is based on the formulation of Kaizen taskforce and improvement of the AUC's standard operational procedures. Furthermore, the New Partnership for Africa's Development (NEPAD) Agency, in collaboration with JICA, has also started promoting Kaizen efforts among the AU member countries from 2016.

In sub-Saharan Africa, Ethiopia is a top runner which has introduced nationwide Kaizen activities, whose details are described by Mekonen in Chap. 5 of this book. One of the key factors that leads to successful Kaizen promotion in Ethiopia is a strong commitment of the government. In 2008, then Prime Minister Meles Zenawi directly requested transfer of Kaizen knowledge from the Japanese government. Meles clearly pointed out to the mission members sent by the JICA headquarters that he wanted the Kaizen approach among other tools of industrial development and business development services. The reason why he had chosen Kaizen can be read in his article (Zenawi 2012), in which he argues about two distinct national innovation systems for economic development. One is the mission-oriented system which is characterized by investments in large public and private research infrastructure for the continuous generation of new ideas and technologies. This system that is found in the UK, US and France is also sustained with relatively high mobility of labor force and capital from mature to new technologies. Another is called the diffusion system that invests more efforts in human resources development which is found in Germany, Japan and Korea. This system is related to higher education and training of engineers/ 
craftsmen to create continuous upgrading of standards. He concludes that while the mission-oriented system is good for the front runner, the diffusion system is effective in mastering existing technologies during the catch-up process in developing countries. Therefore, Meles had deliberately chosen the Japanese Kaizen which is a typical model of innovation under the diffusion system. Because of his clear orientation to Kaizen based on his distinctive policy research, the government of Ethiopia has been enthusiastically scaling-up Kaizen application to both private and public sectors. The government established the Ethiopia Kaizen Institute (EKI) after a year and a half of verification of the applicability of Kaizen to the country. EKI has been very proactive in promoting Kaizen even without involving Japanese experts after mastering basic tools and methodologies. Eye-opening details are described in Chap. 5.

In Ethiopia, there is significant FDI influx into the garment and leather industries in the past decade. Many of them come from Asia, particularly from China, and are practicing some Kaizen tools such as $5 \mathrm{~S}$ in their factories built in Ethiopia. Managers of the factories who came from China or Taiwan are already familiar with these tools even without knowing the origin of Kaizen. They spend huge efforts to train newly recruited young local workers on basic disciplines starting from how to use the toilet and proceeding to the importance of keeping rules and regulations and then technical skills of cutting and sewing. $5 \mathrm{~S}$ is an effective tool for them to teach discipline to these workers. Therefore, the government-led Kaizen promotion in Ethiopia may have good complementarity with its enthusiastic policy of FDI attraction.

Prior to JICA's cooperation with Africa, there are two countries, Burkina Faso and Botswana, that have attempted to transplant Kaizen-type productivity improvement activities in Africa. In Burkina Faso, the World Bank supported Kaizen dissemination from 1989 until 2000 and the United Nations Industrial Development Organization (UNIDO) supported it from 1999 to 2003. Uesu (2011) discussed by citing the report of UNIDO in 2005 that despite some important achievements and the important role of the organization that promoted QCC, the results of application varied between companies and were judged as "mixed." Based on the review of the case in Burkina Faso, Uesu concludes by making 
four ${ }^{12}$ recommendations on Kaizen promotion in developing countries that includes: (1) the government should play a proactive role to encourage the private sector in improving quality and productivity and (2) the imported system should be tailored in accordance with the circumstances and the capacity of the country. Regarding the latter, she explains that the companies that were successful in promoting QCC had made small adjustments in accordance with the difference in employment systems between Japan and Burkina Faso, while others who failed had not.

In Botswana, the NPB in Singapore supported productivity improvement from 1991 to 2000, which is reported by Kitaw (2011). He concludes that the impact of the productivity improvement program in Botswana has not been as high as expected, by referring to the downward trend of the country's rating in the Global Competitive Index, ranked 66th in 2009/2010, 76th in 2010/2011 and 80th in 2011/2012. However, the support by Singapore's NPB had terminated ten years before this downward trend began, so further research is needed. And the conditions of African economies between the stagnating 1990s and the growing 2010s are quite different, so the absorptive capacity of companies and the environment surrounding them in the continent might be different too.

\subsection{Key Lessons and Challenges}

The author picks up three lumps of the lessons learned from the cases of Kaizen promotion in many developing countries in different parts of the world through TC. First, the importance of a set of institutional arrangements must be discussed so as to concretize the foundation of Kaizen promotion. Second, development of core capacities of human resources is important for the entry point of productivity improvement in many developing countries. And core capacity is related to the concept of the Kaizen mind-set, which is always a black box of Kaizen. Needless to say, it is important to understand the inside of the black box. Third, customization of the methodologies and tools is essential in order to create workable systems based on each local context of the country.

\footnotetext{
${ }^{12}$ The other two recommendations are (1) involving and motivating the top management is key and (2) long-term capacity building and institutional building are required.
} 


\subsubsection{Institutional Arrangements}

In Singapore, the NPB was established in 1972 and the Committee of Productivity was established in 1981 as critical steps of the productivity movement before starting the JICA project. In Ethiopia, EKI was established in 2011, after two years since the country was exposed to Kaizen for the first time. For the substantive dissemination of Kaizen, it is crucial for a developing country to establish a specialized organization in charge of promotion, most probably in the public domain if dynamism of the private sector is not strong enough. The role of the government is decisive of triggering and sustaining productivity improvement because required knowledge has the nature of a public good with large spillover effects; thus, transfer of knowledge cannot be optimal in unfettered markets. The organization should be able to receive a sufficient amount of allocated resources for its activities, not only to cover recurrent costs but also capital budget.

Ohno (2011) selects six criteria for successful Kaizen promotion as a national movement: they are (1) strong personal commitment of the top leader, (2) establishment of core organizations responsible for implementation, (3) presence of supporting institutions and mechanisms, (4) implementation of a massive campaign, (5) provision of standardized training programs and (6) enhancement of capability of the private sector. It might be fortunate if all the six criteria are fulfilled at once in many African countries. The establishment of the core organizations and a strong commitment by the government that make a massive campaign possible by using basic tools such as $5 \mathrm{~S}$ are priority issues to create momentum. The commitment of a top visionary political leader is unquestionably important as we saw in Singapore and Ethiopia, though it can be a challenge too. In both countries, the prime ministers took distinctive initiatives of transplanting quality and productivity improvement activities into their own countries.

For effective transfer of technology, ownership of the government in the recipient side is indispensable, which can provide momentum of scaling-up the outputs of the TC project. As the World Bank points out, the 
output of TC tends to be microcosm and limited in impact. This is the nature of TC that aims to create a good replicable model under the environment of the recipient country, which does not necessarily include a scale-up mechanism until the successful model is established. And impacts of the model in the macro-level may not be easily visible in the short term, while the micro-level outcomes are tangible. Therefore, without strong commitment of the recipient government, TC cannot successfully proceed to the scaling-up stage, and be called "supply-driven" by the donor. Therefore, effective institutional setting by the recipient government for the smooth scale-up of Kaizen practices to wider targets than the initial project is a requirement of a successful case.

Furthermore, for the successful Kaizen activities on the floor of factories, firm commitment of the management of a company is an imperative duty. It is very naive to talk about workers' participation only without commitment and leadership of the management of a company. Workers never perform well under poor management in the factory even when applying Kaizen tools and methodologies. Therefore, the organization should be equipped with the capability of sensitizing the managements of companies or to select companies that have motivated managements.

Two challenges must be listed at this point. One is high turnover of the trained staff in the core organization. It is a common challenge of JICA's human resource development projects especially in a country with high mobility of labor in the market. There are two observed countermeasures; one is the case in Ethiopia that creates a monetary and in-kind incentive for the staff to remain in the organization, and another is observed in the cases of Singapore and Paraguay that create a sizable pool of consultants outside of the organization to be mobilized on a contract basis.

Another challenge is the commitment of high-level political leaders. The two successful leaders mentioned repeatedly are highly prominent, wellinformed and visionaries in the history of development. In order to draw commitment of political leaders, it is important to create opportunities for them to be exposed to tangible evidence and successful cases in addition to written information, which should not be a chicken and egg argument. Hence, leaders of Kaizen-implementing organizations need to be strategic to draw and maintain commitment of top political leaderships. 


\subsubsection{Core Capacities and the Kaizen Mind-Set}

Although the abovementioned institutional arrangements can promote the process of human capacity development, there is a substantial issue that often receives less attention in technology transfer, which is development of core capacities. Requirement of sector-specific technologies to produce quality products is evident, so the managements may proactively introduce new techniques/skills and machineries. However, development of core capacities, such as discipline, will and attitude, is a prerequisite to sustain acquisition of technical capacities. For the labor-intensive production lines in a factory, if one person does not properly handle the assigned work, it will affect the quality of final products. Even when automation and mechanization are in progress, safe and accurate operation requires such discipline. In African countries, one of the reasons for low labor productivity seems to be caused by the low level of core capacities, which severely affects organizational capacities and performance of collective work. Lack of punctual time management wastes available time of all the participants in the work process, like a 15-minute delay of the meeting for 8 people wastes 2 hours of person-time. Time is a precious resource that is often neglected in a low-productive work process.

$5 \mathrm{~S}$ is a suitable method for improving core capacities because it focuses on very basic housekeeping issues. It trains people to keep simple rules; for example, every worker has to return a tool, which the worker uses, to the original place after use. The worker has to sort every material in the right order and make them findable for other workers. These simple arrangements of $5 \mathrm{~S}$ are relatively easy to achieve with tangible outputs of productivity improvement in many workplaces, including factories and offices even in Japan now.

We may call core capacities as the mind-set of people. However, the word "mind-set" gives us an image of something difficult to change because of its ambiguous outline. The word mind-set can be disaggregated into more concrete words including motivation and self-confidence. For motivation, JICA is developing an approach to stimulate it in rural development projects named Smallholder Horticulture Empowerment and Promotion (SHEP) based on the Motivation and Self-Determination theory in psychology 
(JICA 2016). For accuracy, daily training with incentive and punishment may work. For self-confidence, accumulation of small successes can be influential. In Ethiopia, the author observed mind-set change as one of the major outcomes of Kaizen promotion because of the weak core capacity of the majority of workers including discipline and punctuality. The author believes that the mind-set of someone is a phenotype of her/his own capability under a certain environment.

Figure 2.3 illustrates a cyclical concept of the Kaizen mind-set. People who have little motivation can create little but tangible improvement by using relatively basic Kaizen tools without any additional resource allocation. The improvement can create little satisfaction and self-confidence, which guide him/her to further target setting and motivation. The outside of cyclical arrows in the figure shows Kaizen tools and promotion measures as extrinsic factors, and the inside shows a concept of Kaizen-type mind-set as intrinsic elements that have a strong link with core capacity. Such mind-set is not a precondition of Kaizen activities but results of the progresses. This cyclical stimulation of mental and occupational improvement can be fueled with small steps of successes and encouragements from outside. Then people may feel like "we can create many improvements" without a fear of change. In

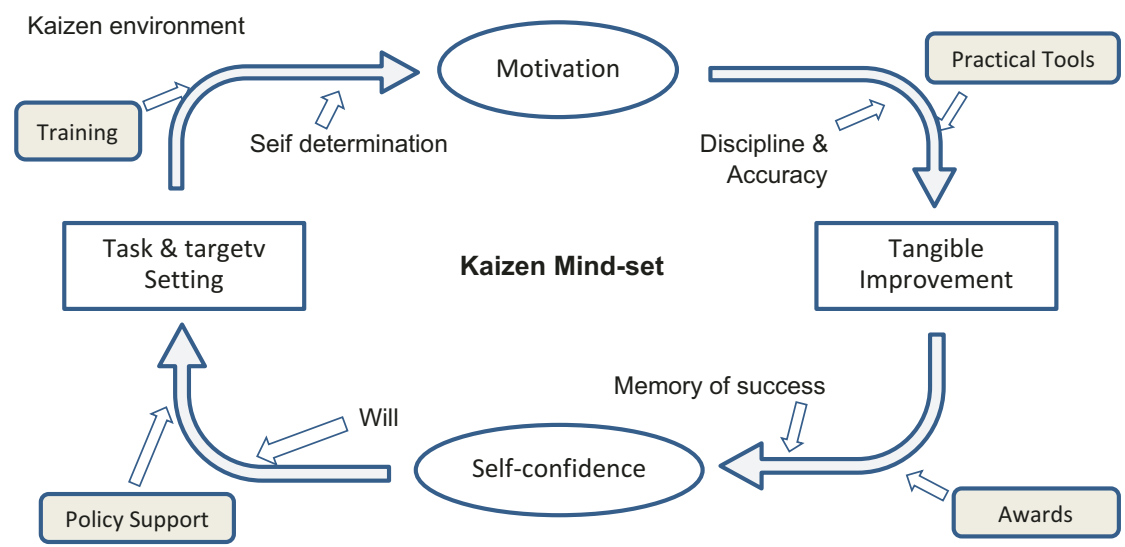

Fig. 2.3 A cyclical concept of the Kaizen mind-set. (Source: Created by the author) 
order to trigger this cycle, a Japanese Kaizen expert asks the factory workers during consultation if they have any production process they feel unsafe or burdensome. Then the expert tries to solve the problem with basic Kaizen tools as to show a tangible result, which convinces the workers that Kaizen is beneficial to them.

A fundamental challenge may be the "cultural aspects" of Kaizen. One of the long-lasting questions on the effectiveness of Kaizen is that it may not be transferable to the society with a different culture because Kaizen is adapted to Japanese culture founded on homogeneity of society and unique religions. The question needs to be answered by demonstrating actual successful cases of transfer, such as Singapore and Ethiopia. In terms of literature, Recht and Wilderom (1998) have studied the effectiveness of the Kaizen-oriented suggestion system in Slovenia and argue that organization culture consists of the employment system, managementworker relation and internal information flow of the company that can be changeable by application of Kaizen even under different national cultures. Perry (1997) analyzes applicability of TQM in Africa and concludes that it might be as easy to introduce into African countries as into other countries because of the high level of collectivism in Africa. However, he adds that it cannot be a simple transplant but it needs be modified to fit in the African context.

\subsubsection{Customization}

The concept of Kaizen that JICA has been transferring to developing countries includes a variety of methodologies and tools. Typical processes of customization are (1) selection of methods and tools based on prevailing problems in the target companies, (2) modification of operational rules of methodologies/tools based on management-labor relations and social problems the company faces and (3) reformulation of methodologies/tools in response to social systems such as education, employment and economic trend. These processes need to be initiated by people who have knowledge and ideas on details of systems and problems.

One of customization observed is a broad application of $5 \mathrm{~S}$ coupled with $5 \mathrm{~S}$ auditing and $5 \mathrm{~S}$ certification developed in many developing 
countries. $5 \mathrm{~S}$ is a popular and easy method for the initial stage of Kaizen introduction, which is also very effective as repeatedly said. Another customization is observed in the project in Singapore in the restructuring stage. Methodology of the technology transfer in Singapore was changed from "a sequence of deepening theoretical understanding first" to "a combination of theoretical classroom training (CRT) and practical incompany training (ICT)" in the short cycle, followed by further on-the-job training, which is a typical approach of learning by doing.

Further customization may be the adjustment of application of methodologies/tools to the common employment systems such as lifetime employment or short-term contract and the wage system. Uesu (2011) points out that the QC circle in Japan is undertaken most often as unpaid voluntary work after working hours, which is difficult to do in the same manner in developing countries. If collectivism among workers is high in the society, group work may be effective like the Kaizen Promotion Team (KPT) in Ethiopia described in Chap. 5. Social coherence and the mutual support system symbolized by the extended family system in Africa seem similar to the one in Asia than in the US. Customization of Kaizen in Africa might be in a different direction from the case in the US and the UK since dynamism of labor mobility in the labor market, style of collectivism shared in society and level of core capacities of people are different between Africa and the US or the UK.

Regarding the guiding principles of the productivity movement, in 1955, the Japanese government and JPC announced three principles: (1) expansion of employment; (2) cooperation between labor and management; and (3) fair distribution of the fruits of productivity improvement among labor, management and consumers, as mentioned before (JPC 2005). African countries may need to have similar but different guiding principles of their own for sustainable Kaizen practices with broad participation of workers. Although increase in wage without productivity increase may negatively affect competitiveness of the company, the managers and workers can agree that wage increase be linked to productivity improvement in order to maintain competitiveness. If this is agreeable, both parties will have incentive to improve productivity.

How to further evolve the Kaizen system under the recent rapid development of information technology is a challenge to be mentioned. Volume 
of data and information accessible to policymakers, consultants, managers, engineers and workers in companies is rapidly increasing through the development of the Internet. Efficiency of communication among stakeholders is increasing drastically by using different information software such as e-mail, text message, social media as well as the Internet of Things. And operation systems and role of workers may change in accordance with the development of information technology (IT) and artificial intelligence (AI). Based on these circumstances, the methodologies and tools of Kaizen can be and should be further developed.

Another, and perhaps a more fundamental, challenge on customization of Kaizen as a device of TC is embedded in its decision-making system of ODA. In many ODA projects, fundamental decision-making on designing and implementation is made at the head office in the home country, even though beneficiaries of the project are in the recipient country. In contrast with domestic development projects of the government, ODA projects tend to have an information gap to conduct smooth monitoring and evaluation. And the donor government is obliged to be accountable to their own taxpayers in the home country. Therefore, the donor organization tends to set a rigid Monitoring and Evaluation (M\&E) framework with a short timeframe of assessment to judge the performance. However, as the author explains, by its nature successful TC needs learning by doing. That means concrete answer on how to solve problems is not exactly known by stakeholders at the early stage of projects. The decision-making process in the head office of donors needs to be sensitive about these aspects and be flexible in operation. Otherwise, the head office may tend to decide its withdrawal from essential but difficult issues and allocate resources to only easy issues with already established methodologies.

\subsection{Conclusions and Implications}

Because knowledge and technologies are essential to our development, their transfer from one society to another is an imperative task to accelerate the process. However, knowledge transfer is not a simple task. Global knowledge needs be localized for effective utilization, and local knowledge can be shared widely and can become a global standard. History shows 
that the process of customization of quality control methods from the US has created Kaizen in Japan, which has become global knowledge. Localization of Kaizen in the African context may create further useful knowledge to accelerate the catch-up process of many people in developing countries. Kaizen, with the fundamental characteristics of a low-cost, gradual and inclusive approach, has huge potential. And Kaizen consists of a wide range of tools from basic to advanced, which also ensures applicability to many people with different capabilities in a variety of countries.

Through reviewing the academic literatures, the reports of past projects and empirical knowledge accumulated in JICA obtained from experiences in Japan, Africa, Asia and Europe, it can be said that quality and productivity improvement through Kaizen methodologies are very effective for Africa. The following are some conclusions on how to introduce Kaizen in African environments.

- For effective transfer of Kaizen, the government and its top leaders can play significant roles through a set of institutional arrangements including creation of and support to the core implementing organization of productivity improvement, allocation of adequate resources to create impacts and promotion of a national movement guided by strong commitment of the top leaders as observed in Singapore and Ethiopia.

- For sustainable improvement of quality and productivity of work, the core capacities need to receive due attention since they provide the bases for further technical capacity development including operation and maintenance skills of machineries and infrastructure. The required efforts to develop core capacity include not only obtaining theoretical knowledge but more essentially learning through actual experiences of trial and error.

- The Kaizen mind-set of people is a result of a continuous and cyclical Kaizen exercise of small successful experiences, self-confidence, further target setting and motivation. This mind-set can be the base of creating change and making proactive contribution to improvement.

- Since knowledge transfer is influenced by both technical and human aspects, the process of customizing Kaizen tools and methodologies in the local context while maintaining the core value of Kaizen is indispensable for long-lasting quality and productivity improvement activities. 
Apart from these human aspects, details of the technical feature of the Kaizen system, methodologies and tools are described in Chap. 3. Some of the technical tools are much more scientific, objective and universally applicable than the above features. And how to justify Kaizen and maximize its effects in a broader context of industrial development are further points discussed in Chap. 6 as it has been playing in economic growth in Southeast Asian countries.

When we cannot do things smoothly, we may ask two questions to ourselves, namely "are we doing right things?" and "are we doing things right?" It is already proven that Kaizen is applicable in many workplaces in a different environment in its entirety or in part. The right question is how to apply Kaizen in the African context. JICA's effort on standardization of Kaizen along the African context focuses precisely on this question through sorting out know-how obtained from customization in each country and sharing with others (see Chap. 4). Needless to say, success needs active contribution of people in Africa.

\section{References}

Arase, D. (2005). Introduction. In D. Arase (Ed.), Japan's Foreign Aid, Old Continuities and New Directions (pp. 1-19). Oxon: Routledge.

Chambers, R. (1997). Who's Reality Counts? Putting the First Last. Rugby: Practical Action Publishing.

Cirera, X., \& Maloney, W. (2017). The Innovation Paradox, Developing-Country Capabilities and the Unrealized Promise of Technological Catch-Up. Washington, DC: World Bank Group.

Easterly, W. (2006). The White Man's Burden. New York: Oxford University Press.

Imai, M. (2012). Gemba Kaizen Second Edition: A Commonsense Approach to a Continuous Improvement Strategy. New York: McGraw-Hill.

Japan International Cooperation Agency. (1986). Singapore Kyowakoku Seisansei Kojo Project (Asean Hitozukuri Project) Sogo Chosa Hokokusho (Comprehensive Study Report on Productivity Development Project in Singapore), ASEAN Human Resources Development Project, JICA Kokaigi JR-86-54. 
Japan International Cooperation Agency. (1997). Kokogyo Project Follow-Up Chosa (Kaizen) Hokokusho, Dai Ichi Bunsatsu, Dai Ichi-bu, Kaizen Donyu wo Chushintoshita Seisansei Kojo Gijutsu Iten (Report of the Follow-Up Study on Projects in Mining and Industry Sector (Kaizen), Part 1 of Volume 1 Technology Transfer of Productivity Improvement focusing on introduction of Kaizen), JICA Kochokei JR-07-114.

Japan International Cooperation Agency. (1999). Thai Okoku Seisansei Kojo Project Shuryoji Hyoka Hokokusho (Terminal Evaluation Report on Productivity Development Project in the Kingdom of Thailand), JICA Kokai-1 JR-99-19.

Japan International Cooperation Agency. (2000a). Thai Okoku Seisansei Kojo Project (Follow up) Shuryoji Hyoka Hokokusho (Terminal Evaluation Report on Productivity Development Project Follow up in the Kingdom of Thailand), JICA Kokai-1 JR-00-38.

Japan International Cooperation Agency. (2000b). Brasil Renpokyowakoku Seisansei/hinshitu Kojo Shuryoji Hyoka Hokokusho (Terminal Evaluation Report on Improvement of Productivity and Quality Control in Federative Republic of Brazil), JICA Kokai-1 JR-00-09.

Japan International Cooperation Agency. (2004). Asean Chiikini Okeru Susonosangyo Ikusei Kyoryoku Jigyo no Arikatani Kansuru Kisochosa Hokokusho (Basic Study Report on Cooperation Projects Focusing on Development of Supporting Industry in ASEAN Region), JICA Keizai-JR-04-040.

Japan International Cooperation Agency. (2005). Costa Rica Seisansei Kojo Project Shuryoji Hyoka Chosadan Hokokusho (Report of the Terminal Evaluation Mission for Productivity Improvement Project in Costa Rica), JICA Keizai JR-05-121.

Japan International Cooperation Agency. (2008). Capacity Assessment Handbook: Project Management for Realizing Capacity Development. Tokyo: JICA Research Institute.

Japan International Cooperation Agency. (2009). Paraguay Kyowakoku Hinshitsu Seisansei Center Kyoka Keikaku Project Shuryoji Hyoka Hokokusho (Terminal Evaluation Report of the Project for Strengthening Quality and Productivity Center in Paraguay Republic), JICA Sangyo JR-09-109.

Japan International Cooperation Agency. (2014a). Costa Rica Chushokigyo no Hinshitsu Seisansei Kojo ni Kakaru Facilitator Noryoku Kojo Project, Chubei Karibu Koiki: Shuryoji Hyoka Hokokusho (Terminal Evaluation Report of the Regional Project, Central America and Caribbean Countries: On Capacity 
Development of Facilitators for Quality and Productivity Improvement in SMEs

Hosted by Costa Rica). Tokyo: Japan International Cooperation Agency. Japan International Cooperation Agency. (2014b). Feature, 60 Years of Japanese

ODA: History, The Kaizen Project, Laying the Groundwork for Singapore's

Growth. JICA's World January, 4-5.

Japan International Cooperation Agency. (2016). Introduction to the Psychology

of International Cooperation, Seventeen Motivation Case Studies Collected from the Field. Tokyo: Japan International Cooperation Agency.

Japan International Cooperation Agency, UNICO International, and Japan

Productivity Center. (2018). Project Kenkyu Africa Kaizen Shien-ni-kakaru,

Hyojun Approach Sakutei Chosa (Study on Standardizing Kaizen Approaches for

Further Dissemination and Deployment in Africa). Tokyo: Japan International

Cooperation Agency.

Japan Productivity Center. (1990). Singapore Seisansei Kojo Project, ASEAN

Hitozukuri Project Gijutsu Iten-no Rinen to Jissen ni Kansuru Hokokusho.

Tokyo: Japan Productivity Center.

Japan Productivity Center. (2005). Seisansei Undo 50nenshi. Tokyo: Japan

Productivity Center.

Kato, H. (2016). Japan's ODA 1954-2014: Changes and Continuities in a

Central Instrument in Japan's Foreign Policy. In H. Kato, J. Page, \&

Y. Shimomura (Eds.), Japan's Development Assistance, Foreign Aid and the Post2015 Agenda. Hampshire: Palgrave Macmillan.

Killick, T. (2008). Understanding British Aid to Africa: A Historical Perception.

In GRIPS Development Forum Report; Diversity and Complementarity in Development Aid, http://www.grips.ac.jp/forum-e/D\&CinDA.htm

King, K., \& McGrath, S. (2004). Knowledge for Development? Comparing British, Japanese, Swedish and World Bank Aid. London: Zed Books.

Kitaw, D. (2011). Chapter 5 Botswana's Productivity Movement. In Kaizen

National Movement, a Study of Quality and Productivity Improvement in Asia and Africa. Tokyo: JICA-GRIPS.

Kodera, K. (2016). Japan's Engagement with Multilateral Development Banks:

Do Their Professional Paths Really Cross? In H. Kato, J. Page, \& Y. Shimomura (Eds.), Japan's Development Assistance, Foreign Aid and the Post-2015 Agenda (pp. 19-35). Hampshire: Palgrave Macmillan.

Lemma, A. (2016). The Role of Kaizen in Economic Transformation. London: Overseas Development Institute. https://www.odi.org/publications/11067role-kaizen-economic-transformation

McMahon, G. (1997). Applying Economic Analysis to Technical Assistance Projects.

Washington, DC: World Bank. 
Ministry of Economy, Trade and Industry (METI). (2005). Wagakuni no Keizai Kyoryoku no Seikokeiken wo Fumaeta Japan ODA Model no Suishin (Promotion of Japan ODA Model Based on the Success of Economic Cooperation), Interim Report of the Working Group of Economic Cooperation, the National Council of Industrial Structure. Tokyo: Ministry of Economy, Trade and Industry.

Morrison, K. (2005). The World Bank, Japan and Aid Effectiveness. In D. Arase (Ed.), Japan's Foreign Aid, Old Continuities and New Directions (pp. 23-40). Oxon: Routledge.

National Productivity Board (NPB) and Japan International Cooperation Agency (JICA). (1990). Further Fields to Conquer... A PDP Commemorative Publication. Singapore/Tokyo: National Productivity Board/JICA.

Nonaka, I. (1991, November-December). The Knowledge-Creating Company. Harvard Business Review, 96-104.

Nonaka, I., \& Toyama, R. (2003). The Knowledge-Creating Theory Revisited: Knowledge Creation as a Synthesizing Process. Knowledge Management Research and Practice, 1(1), 2-10.

Ohno, I. (2011). Chapter 1 Overview: National Movements and the Synthesis of Selected Country Experiences. In Kaizen National Movement, a Study of Quality and Productivity Improvement in Asia and Africa. Tokyo: JICA-GRIPS.

Ohno, I., \& Kitaw, D. (2011). Chapter 3 Productivity Movement in Singapore. In Kaizen National Movement, a Study of Quality and Productivity Improvement in Asia and Africa. Tokyo: JICA-GRIPS.

Perry, C. (1997). Total Quality Management and Reconceptualizing Management in Africa. International Business Review, 6(3), 233-243.

Recht, R., \& Wilderom, C. (1998). Kaizen and Culture: On the Transferability of Japanese Suggestion System. International Business Review, 7(1), 7-22.

Sawamura, N. (2002). Local Spirit, Global Knowledge: A Japanese Approach to Knowledge Development in International Cooperation. Compare: A Journal of Comparative and International Education, 32(3), 339-348.

Stiglitz, J., \& Greenwald, B. (2014). Creating Learning Society. New York: Colombia University Press.

Uesu, S. (2011). Chapter 4 Quality Control Circles in Burkina Faso: Lessons Learned and Implications for Other Developing Countries. In Kaizen National Movement, a Study of Quality and Productivity Improvement in Asia and Africa. Tokyo: JICA-GRIPS. 
World Bank (WB). (1996). Lessons \& Practices: Technical Assistance. Washington, DC: Operations Evaluation Department, World Bank.

Zenawi, M. (2012). States and Markets: Neoliberal Limitations and the Case for a Developmental State. In A. Noman et al. (Eds.), Good Growth and Governance in Africa, Rethinking Development Strategies. New York: Oxford University Press.

Open Access This chapter is licensed under the terms of the Creative Commons Attribution 4.0 International License (http://creativecommons.org/licenses/ by/4.0/), which permits use, sharing, adaptation, distribution and reproduction in any medium or format, as long as you give appropriate credit to the original author(s) and the source, provide a link to the Creative Commons license and indicate if changes were made.

The images or other third party material in this chapter are included in the chapter's Creative Commons license, unless indicated otherwise in a credit line to the material. If material is not included in the chapter's Creative Commons license and your intended use is not permitted by statutory regulation or exceeds the permitted use, you will need to obtain permission directly from the copyright holder.

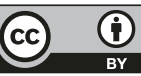

